\title{
BURNUP CALCULATIONS OF THE JSI TRIGA REACTOR FUEL AND COMPARISON WITH MEASUREMENTS
}

\author{
Anže Pungerčič $\check{c}^{1,2}$, Dušan Čalič ${ }^{2}$, and Luka Snoj ${ }^{1,2}$ \\ 1"Jožef Stefan" Institute, Reactor Physics Department \\ Jamova cesta 39, Ljubljana, Slovenia \\ ${ }^{2}$ University of Ljubljana, Faculty of mathematics and physics \\ Jadranska cesta 19, Ljubljana, Slovenia \\ anze.pungercic@ijs.si,dusan.calic@ijs.si,luka.snoj@ijs.si
}

\begin{abstract}
Fuel burnup of the JSI TRIGA was calculated by simulating complete operational history consisting of 240 different core configurations from 1966 to 2020. At the moment we are unable to perform burnup measurements, e.g. gamma spectroscopy on burned fuel elements, hence we used weekly measured excess reactivity as a reference point of different core configurations to verify the calculated core reactivity. Changes in reactivity due to burnup were assumed to be linear and this assumption was verified for burnup intervals smaller than $3 \mathrm{MWd} / \mathrm{kg}(\mathrm{HM})$. The comparison was performed on 46 different core configurations with different type of fuel elements. The Serpent- 2 calculations decently predict the rate of reactivity change on different cases, as $52 \%$ of calculations are withing $1 \sigma$ and $86.9 \%$ within $2 \sigma$ of the measurements for total number of 46 cases. Additional analysis was performed by comparing unit cell calculations of different fuel types. Four different types of TRIGA fuel were used to analyse burnup changes in LEU and HEU fuel, where positive reactivity feedback on burnup was observed for HEU fuel due to burnable absorbers. Serpent-2 and WIMSD-5B were compared on unit-cell basis where good agreement within $200 \mathrm{pcm}$ of reactivity change for large burnup was observed. In addition neutron spectrum changes due to burnup were investigated using unit-cell calculations where $4 \%$ increase of the thermal peak and $1 \%$ decrease of fast peak of the spectrum was observed for typical fuel burnups of $20 \mathrm{MWd} / \mathrm{kg}(\mathrm{HM})$, which approximately represents JSI TRIGA burnup at this moment.
\end{abstract}

KEYWORDS: Burnup, TRIGA, Reactivity, Serpent-2, Validation, TRIGLAV 


\section{INTRODUCTION}

Determination of fuel burnup in nuclear reactors is important from the standpoint of fuel management, safeguards and radiation protection. Most optimal approach to determine fuel burnup is using computer simulations and compare the calculated results to measured values. Measurements can be performed using gamma spectroscopy to determine isotopic composition of irradiated fuel. As we are unable to perform such measurements at this moment we have decided to find another approach to validate our burnup calculations.

The JSI TRIGA reactor has been in operation since 1966 and in this time core configuration has been changed in total 240 times. We analysed the complete TRIGA operation by collecting and digitalizing each core configuration and each fuel history operation. This data allowed us to perform detailed burnup calculations [1] using modern Monte Carlo neutron transport code Serpent-2 [2] and in-house developed deterministic TRIGLAV [3]. We validated the calculated values by comparing the calculated reactivity changes with weekly measured excess reactivities.

In the first part of the paper the validation results using excess reactivity measurements and calculation results for over more than 50 years in the JSI TRIGA reactor are presented. The main part of this paper is focused on the physics of reactivity changes in the TRIGA reactor, where we explain the assumptions used in the validation on 46 different core configurations, which is presented in the last part.

\section{MEASUREMENTS OF EXCESS REACTIVITY}

Since the start of the operation in 1966 the zero power xenon free excess reactivity is determined every Monday. This means that all reactivity measurements are without xenon contribution since the TRIGA reactor usually does not operate during the weekends. Changes in excess reactivity are directly connected to either fuel burnup or fuel shuffling as presented on right graph of Fig. 1. In addition the rate of change is depended on burnup history, fuel types and core configurations, which is closely examined in this paper. By using the measured reactivity change for validation we could examine the burnup change between two consecutive core configurations by calculating the change of reactivity of two core configurations due to fuel shuffling and fuel burnup. Therefore we decided to analyse all 2000 measurements, presented on left graph of Fig. 1.

Uncertainty in measured excess reactivity are difficult to evaluate since they depend on small changes in the reactor core. An absolute individual reactivity measurement has $1 \sigma$ uncertainty larger than $500 \mathrm{pcm}$ [4], due to control rod-worth measurements [5], reactor physical parameters [6] and power redistribution due to control rod insertion [7]. In the analysis of relative changes in excess reactivity, the assumed uncertainty is much smaller as same control rod-worth measurements are being used and the changes in reactor physical parameters and flux redistribution are negligible if core configuration is the same. 

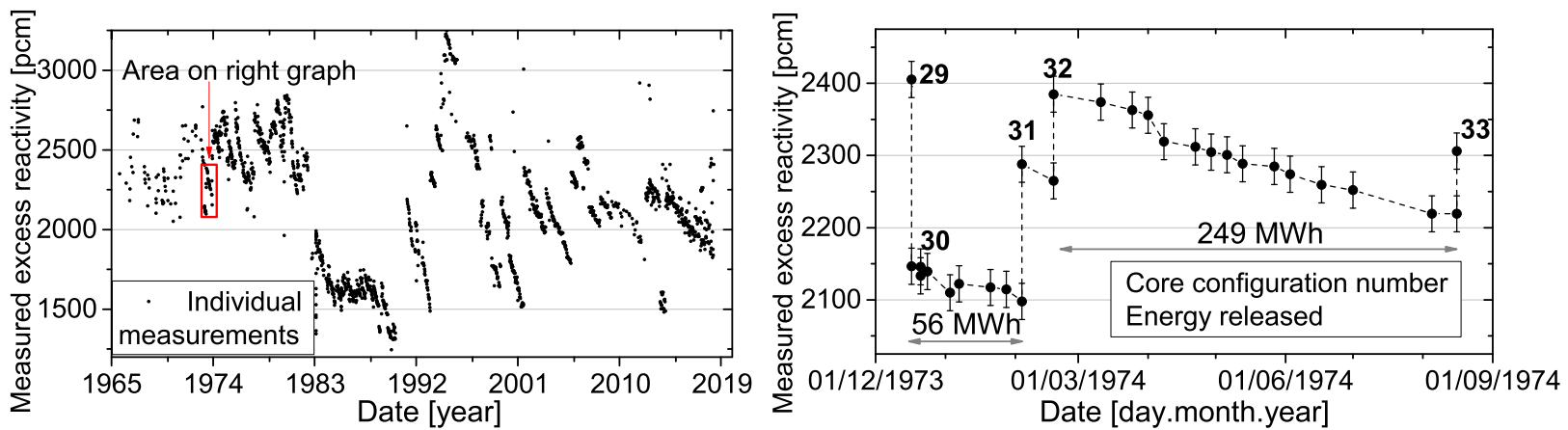

Figure 1: Measurements of excess reactivity performed at the JSI TRIGA reactor for the complete operational history (left) and selected period of 9 months (right), where four core configuration changes were employed in this period. Energy released during operation on core conf. No. 30 and 32 are depicted.

\section{METHODS OF CALCULATING BURNUP}

The methodology used to calculate JSI TRIGA burnup is presented in detail in [1] and only a brief description of the important parts for this analysis is given in this paper. All burnup calculations assume the maximum power release of a specific core configuration. Detailed isotopic composition of each fuel element (total 300 fuel elements) during the burnup history (total 240 core configurations) was considered. In the whole history four different types of fuel element were used. Monte Carlo code Serpent-2 [2] and in-house developed TRIGLAV [3] were used.

Serpent-2 neutron transport and burnup code has already been established as a powerful code for reactor burnup simulations [8]. We used the validated computational model [9] of the JSI TRIGA reactor to model all core configurations and use the data of each fuel burnup history where fuel element region is treated as one depletion zone.

TRIGLAV is a tool for the computational analysis of the TRIGA Mark II reactors based on lattice transport code WIMSD-5B for unit cell cross section homogenization and four group diffusion theory in $2 \mathrm{D}$ cylindrical coordinates. In this paper unit cell calculations were performed using WIMSD-5B code [10].

\section{PHYSICS OF REACTIVITY CHANGES IN TRIGA REACTORS}

\subsection{Assumption of Linear Changes}

In total we have analysed more than 2000 measurements of excess reactivity on different core configurations, which resulted in 20 or more measurements on a single core configuration. As comparing each individual measurement with Monte Carlo calculation is extremely time consuming, we have decided to use linear fitting to analyse changes of reactivity by taking into account all the measured points. As the comparison was conducted on smaller burnup intervals, ranging from $0.2 \mathrm{MWd} / \mathrm{kg}(\mathrm{HM})$ to $3 \mathrm{MWd} / \mathrm{kg}(\mathrm{HM})$, we fitted linear function on the reactivity changes. This assumption was justified by analysing different burnup intervals of a typical TRIGA core burnup. 
Serpent- 2 was used to calculate changes in excess reactivity on a typical core configuration using standard commercial TRIGA fuel elements of $20 \mathrm{wt} . \%$ enrichment and $12 \mathrm{wt} . \%$ uranium concentration. Burnup calculation was performed for up to $30 \mathrm{MWd} / \mathrm{kg}(\mathrm{HM})$ which represents maximum burnup achieved in the JSI TRIGA reactor [1]. Burnup intervals of $3 \mathrm{MWd} / \mathrm{kg}(\mathrm{HM})$ were closely examined and tested for linear assumption as this also justifies all the smaller intervals. Above average core burnup of $4 \mathrm{MWd} / \mathrm{kg}(\mathrm{HM})$ linear approximation can be assumed for longer burnup intervals than at the beginning since the changes in reactivity are governed by linear changes in material density of ${ }^{235} \mathrm{U},{ }^{239} \mathrm{Pu},{ }^{143} \mathrm{Nd}$, etc. [11]. However the linear approach can not be used for smaller core burnups due to ${ }^{149} \mathrm{Sm}$ which reaches its equilibrium at approximately $4.5 \mathrm{MWd} / \mathrm{kg}(\mathrm{HM})$, which can be observed in Fig. 3.

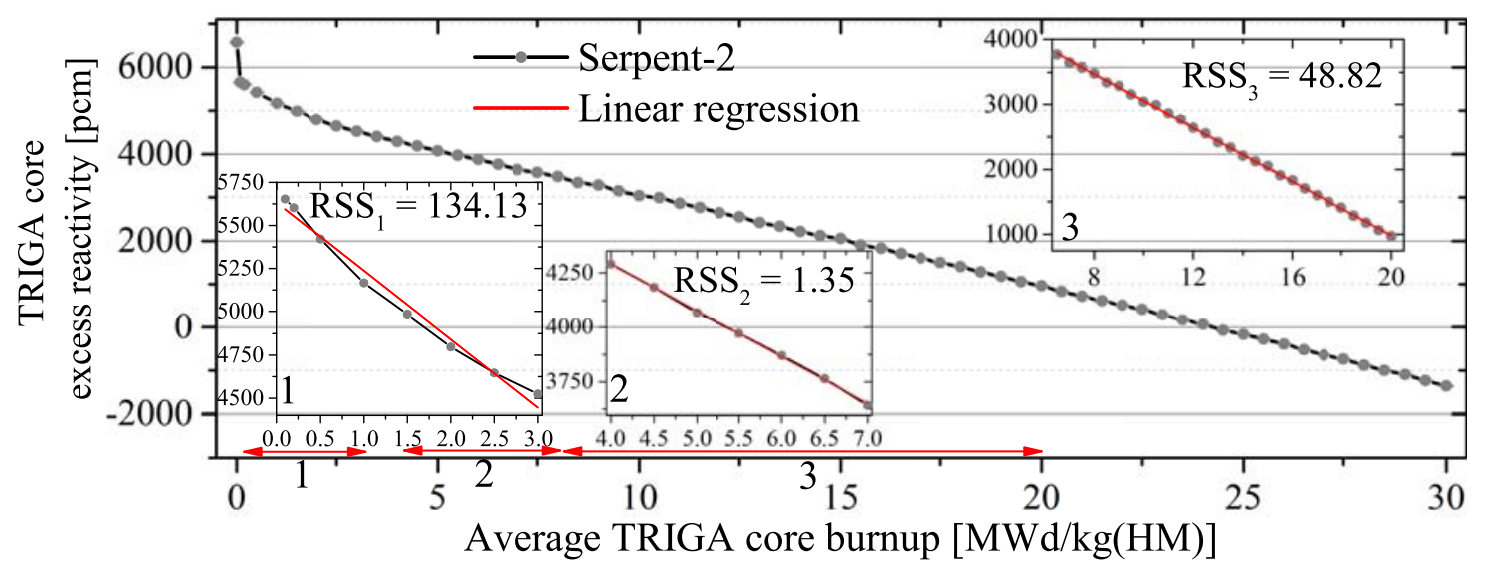

Figure 2: Linear assumption analysis of excess reactivity change in a TRIGA research reactor. For each linear fit Residual Sum of Squares $\left(R S S=\sum_{i=1}^{n}\left(\rho_{\text {meas. }}-\rho_{\text {calc. }}\right)^{2}\right)$ is written showing the quality of fit.
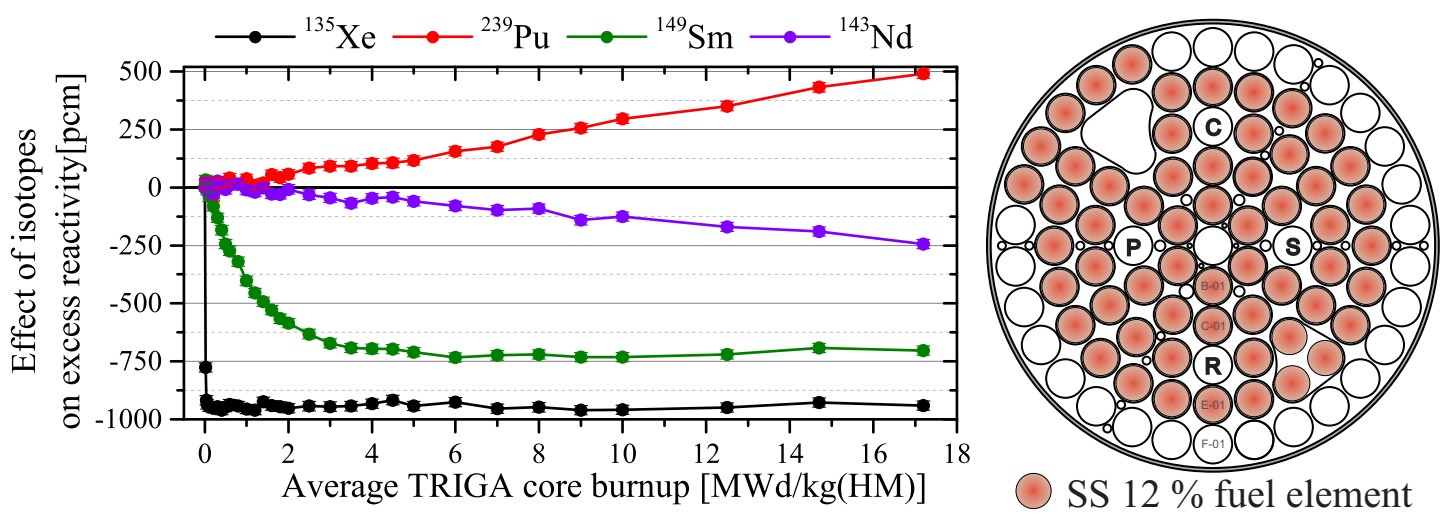

Figure 3: Effect of four important isotopes on reactor core reactivity at different average core burnups (left). Core schematic used in the analysis is depicted on the right.

As this case showed the conservative scenario we can conclude that linear approximation can be assumed for intervals of $3 \mathrm{MWd} / \mathrm{kg}(\mathrm{HM})$ for average core burnups bigger than $4 \mathrm{MWd} / \mathrm{kg}(\mathrm{HM})$ and also for mixed cores where fresh fuel is mixed with already burned ones as those have ${ }^{149} \mathrm{Sm}$ already 
in the equilibrium and the change is not as profound. The limits of linear assumption showed here were taken into consideration during the validation as no cores with average burnup less than 4 $\mathrm{MWd} / \mathrm{kg}(\mathrm{HM})$ were included into analysis and the intervals chosen were smaller at lower burnups.

\subsection{Effect of Fuel Type}

In the complete operational history of the JSI TRIGA reactor, four different types of fuel elements were in use, varying in cladding type (aluminium-Al or stainless steel-SS), amount of uranium in U-Zr-H mixture (8.5 wt.\% or $12 \mathrm{wt} . \%)$ and enrichment (19.9\% and $70 \%)$. Highly enriched fuel, so-called FLIP, has also erbium in the mixture as a burnable absorber.

For each type of fuel element unit-cell was assumed as a fuel pin surrounded with water and with reflective boundary conditions. Same unit cell geometry is used in the TRIGLAV code, where homogenized cross sections are generated at unit-cell level with WIMSD-5B [10]. Serpent-2 and WIMSD-5B were used to calculate changes in unit-cell reactivity and neutron spectrum for burnups up to $30 \mathrm{MWd} / \mathrm{kg}(\mathrm{HM})$. The assumed power density for all fuel elements was $30 \mathrm{MW} / \mathrm{kg}(\mathrm{HM})$. Results of reactivity changes, together with dimensions of individual fuel pins are presented on Fig. 4. Comparison of neutron lethargy spectrum and its change due to burnup is presented on Fig. 5.
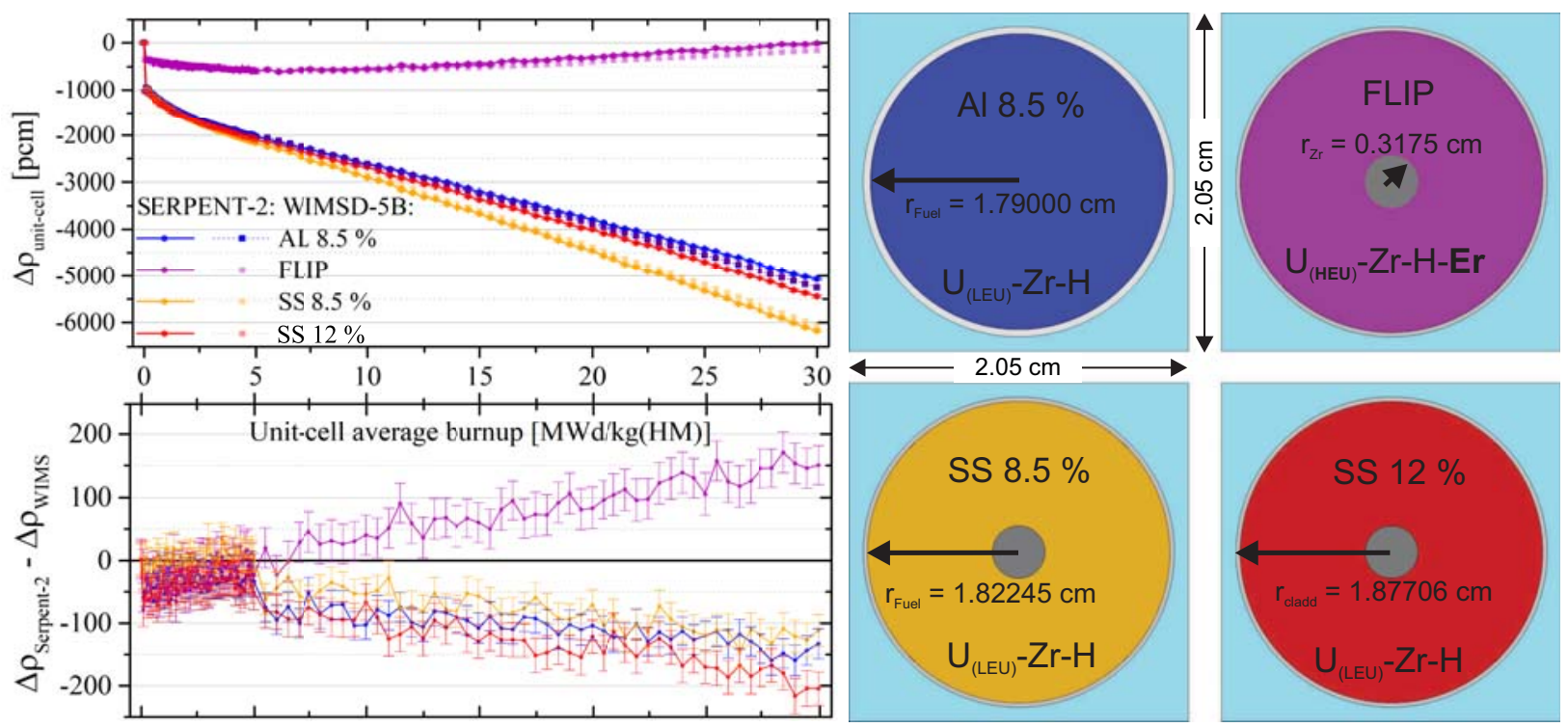

Figure 4: Changes of excess reactivity due to unit-cell burnup for four different types of TRIGA fuel. Serpent-2 results are compared to WIMSD-5B.

The changes in reactivity on unit-cell level show similar behaviour compared to full core calculations. There is visible difference between SS 8.5\% and Al 8.5\%, meaning that the inner Zirconium pin has notable effect on burnup changes. All three low enriched uranium (LEU) fuel elements show similar behaviour with slight difference of faster reactivity decrease for SS $8.5 \%$. Noticable differences can be observed for high enriched uranium (HEU) FLIP fuel with burnable absorbers as after average burnups of $5 \mathrm{MWd} / \mathrm{kg}(\mathrm{HM})$ reactivity increases linearly with burnup, mean- 
ing a positive reactivity feedback on core burnup. It should be noted that all the changes presented here vary on specific power of each fuel pin and that FLIP fuel elements were always used in mixed core configurations resulting in a negative reactivity feedback on core burnup.

A comparison between WIMSD-5B and Serpent-2 was also performed, where good agreement (between -200 and $+200 \mathrm{pcm}$ ) for all fuel types was observed. From this we can conclude that burnup unit-cell calculation performed with WIMSD-5B in the TRIGLAV code is not the source of discrepancies we have observed when comparing to the measurements. Highest discrepancies were observed in core configurations with different types of fuel elements mixed.

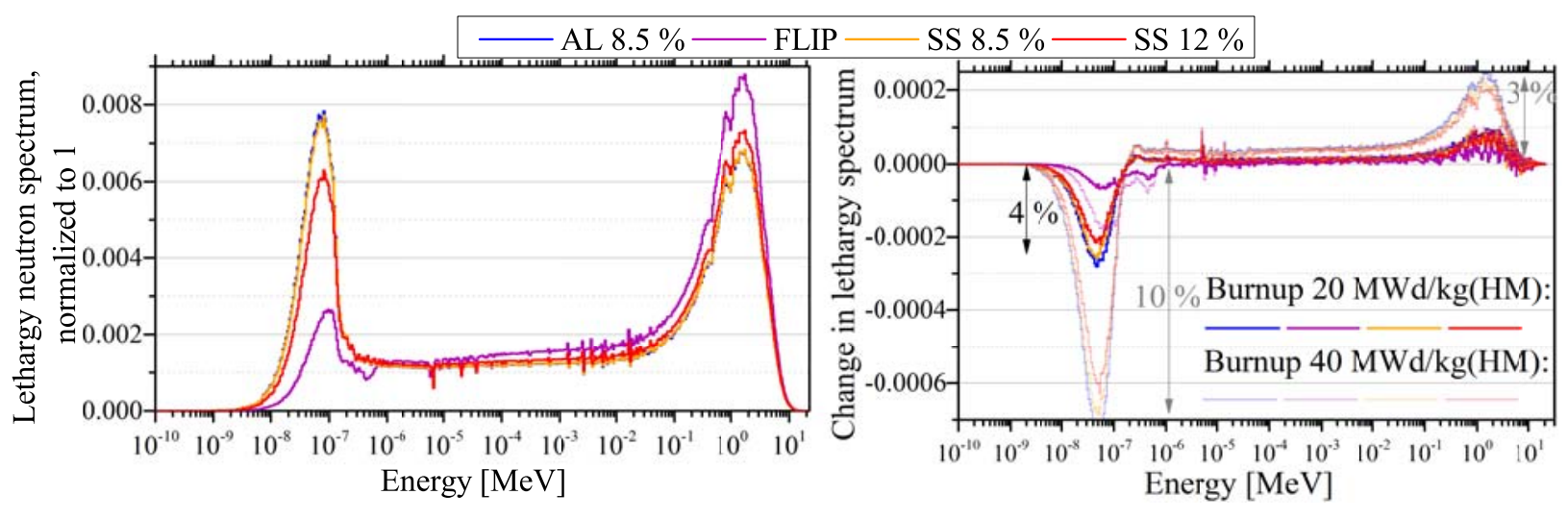

Figure 5: Neutron lethargy spectrum in different types of TRIGA fuel unit-cells (left). Analysis of spectrum changes on two different burnups (right).

We have also analysed the changes in neutron spectrum due to fuel burnup for each type of fuel element. First at typical burnup $20 \mathrm{MWd} / \mathrm{kg}(\mathrm{HM})$ and second at $40 \mathrm{MWd} / \mathrm{kg}(\mathrm{HM})$. No visible shift in the spectrum can be observed only the change of intensity of thermal and fast peak. In all three LEU cases the thermal peak increased by $4 \%$ at $20 \mathrm{MWd} / \mathrm{kg}(\mathrm{HM})$ and $10 \%$ at $40 \mathrm{MWd} / \mathrm{kg}(\mathrm{HM})$ and fast decreased by $1 \%$ and 3\%, respectively. For HEU FLIP fuel type the spectrum changes at $20 \mathrm{MWd} / \mathrm{kg}(\mathrm{HM})$ are observed to be below $1 \%$. We can conclude that at the level of burnup of the current JSI TRIGA fuel (SS $12 \%$ ) the spectrum changes due to burnup are not entirely negligible.

\section{VALIDATION OF BURNUP CALCULATIONS}

So far we have shown that the rate of change of reactivity due to burnup is highly dependant on fuel type and fuel burnup. For this analysis we have chosen the core configurations where the burnup increment is substantial and where the measurements were performed regularly. In total 46 core configurations were chosen, resulting in total of 2000 measurements used in the analysis. 26 out of those core configurations were used before the JSI TRIGA reconstruction in 1991 and consisted mostly of mixtures between Al, SS $8.5 \%$ and FLIP type fuel elements while the core configurations after the reconstruction mostly use fuel elements type SS $12 \%$. Part of the results for selected three core configurations with their core schematics are presented in Fig. 6.

Results obtained from the burnup calculations were compared with measurements. For this purpose we have defined the linear coefficient of reactivity change due to burnup: $\Delta \rho_{\text {Excess }} / \Delta$ Burnup. 


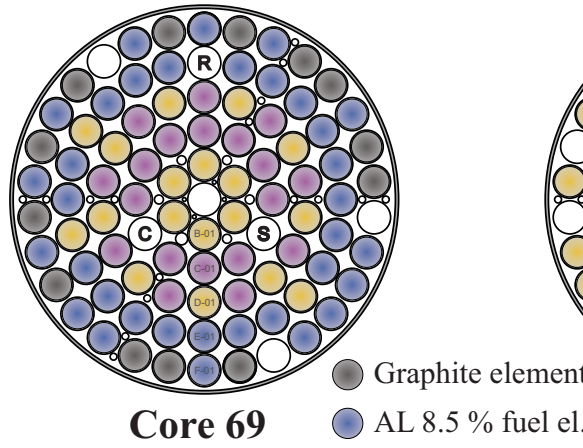

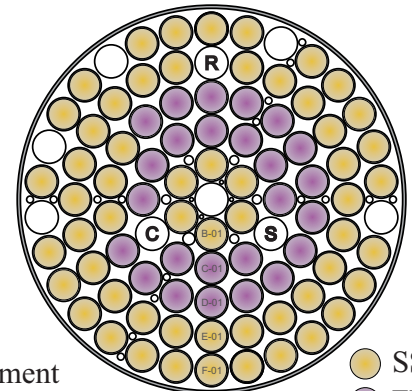

Core 129
SS $8.5 \%$ fuel el.

FLIP fuel el.

SS $12 \%$ fuel el. Cores 216 - 232

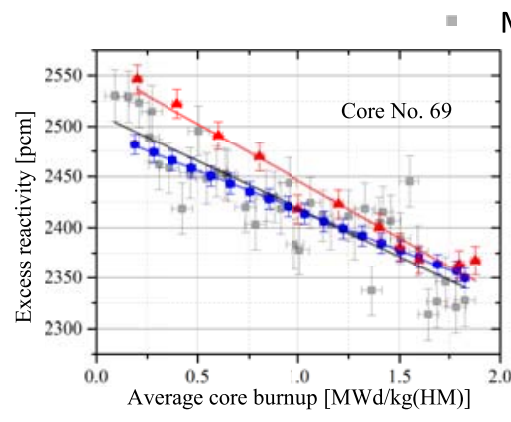

Measurements - TRIGLAV $\Delta$ Serpent

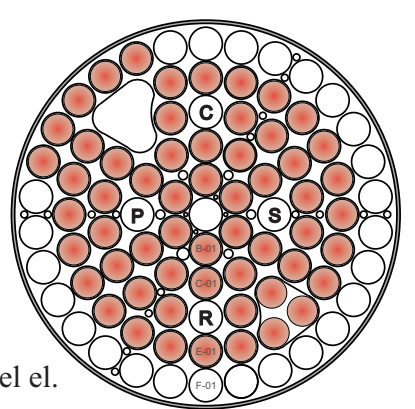

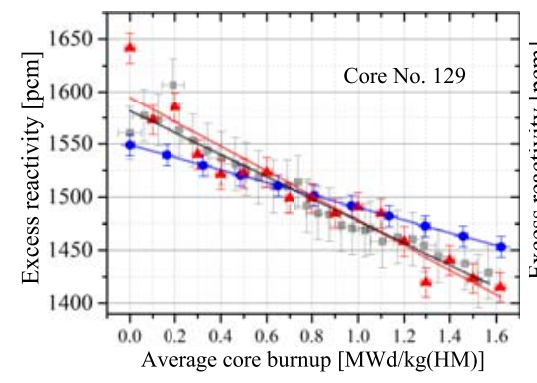

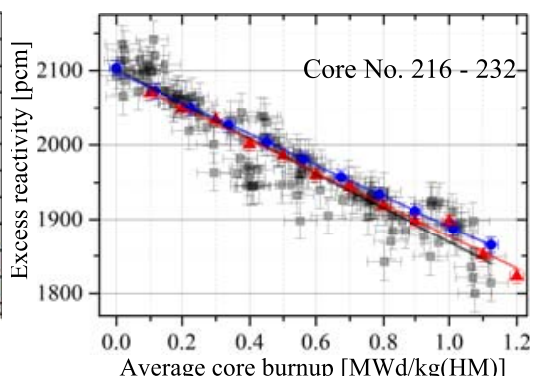

Figure 6: TRIGA core excess reactivity (bottom) as a function of average core burnup for three different core configurations (top). For each core measurements are compared to Serpent- 2 and TRIGLAV burnup calculations. It should be noted that the presented graphs represent only 3 out of 46 analysed cycle excess reactivity changes. Core configurations 216 232 represent multiple identical loading patters.

Fig. 7 presents the results for all 46 analysed core configurations. For starting core configurations the decrease of measured coefficient is observed. This is due to the gradual insertion of FLIP fuel elements that contain burnable absorber erbium, which reduce the negative reactivity change with the burnup as we have observed in the previous section. Similar observation can be made when comparing core configurations before and after reconstruction, as the coefficients are higher after core No. 138 (first core conf. after reconstruction was No. 132). All of the recorded changes are well predicted by both burnup codes TRIGLAV and Serpent as clear change after the reconstruction is observed. An average and the median (presented in Tab. 1) for Serpent-2 are similar and close to zero, meaning that no systematic discrepancy can be observed. On the other hand clear systematic discrepancy can be observed for the TRIGLAV code.

For the comparison of each core coefficient relative difference between calculations and measurements was analysed. The results are presented on the bottom graph of Fig. 7. In general smaller relative differences are observed in coefficients after the reconstruction since the procedure and frequency of reactivity measurements has improved. Also the coefficients calculated with the TRIGLAV code show constantly smaller values that the measurements, which could be due to the method used in the TRIGLAV code. 

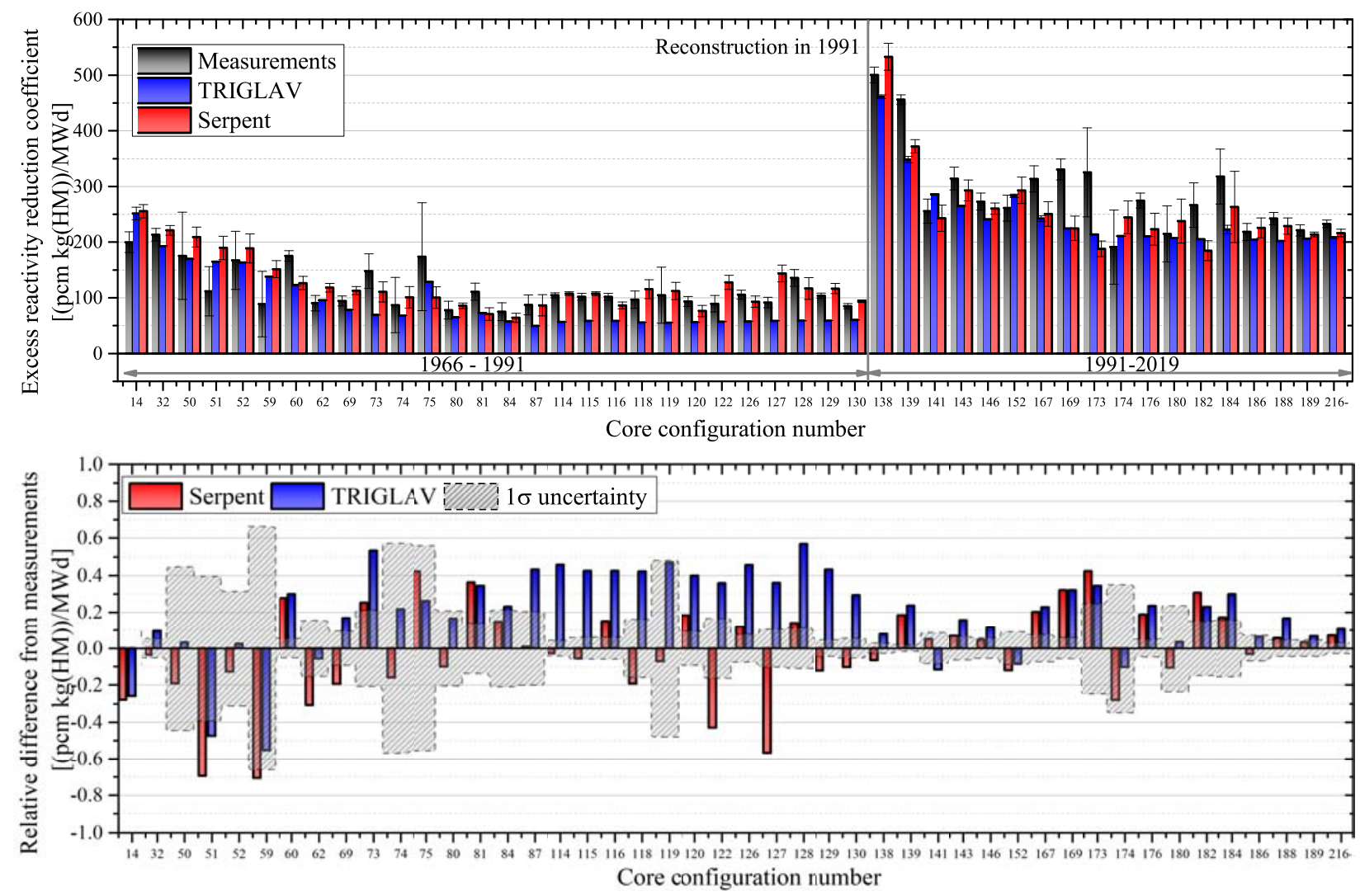

Figure 7: Excess reactivity reduction coefficient for $\mathbf{4 6}$ different core configurations (top graph) throughout the JSI TRIGA operational history. Measurements are compared to Serpent-2 and TRIGLAV calculations. Bottom graph presents relative difference between measurements and calculations with its one sigma uncertainty, defined as

$$
\sigma_{\text {diff }}=\sqrt{\sigma_{\text {calc. }}^{2}+\sigma_{\text {meas. }}^{2}} \text {. }
$$

Table 1: Statistical analysis of differences between the measured and calculated linear burnup reactivity coefficient. Total number of coefficients is 46 , which represent 46 different core configurations and 2000 measurements of excess reactivity in total.

\begin{tabular}{|l|cccc|}
\hline $\begin{array}{l}\text { Analysis of } 46 \text { differences between } \\
\text { calculations and measurements }\end{array}$ & Average & Median & Within $1 \sigma$ & Within $2 \sigma$ \\
\hline $\begin{array}{l}\text { Serpent }-2 \\
\text { TRIGLAV }\end{array}$ & $-1.8 \%$ & $-1.0 \%$ & $24(52.2 \%)$ & $40(86.9 \%)$ \\
\hline
\end{tabular}

\section{CONCLUSION}

In this paper TRIGA burnup calculations are presented and compared to measurements using weekly measured excess reactivity. For the burnup intervals not grater than $3 \mathrm{MWd} / \mathrm{kg}(\mathrm{HM})$ we have 
fitted the burnup change with linear approximation. We have shown that the rate of core reactivity change due to fuel burnup highly depends on the type of TRIGA fuel as four different fuel types were investigated and positive reactivity feedback on burnup was observed for HEU with burnable absorbers. Based on the analysis from the first step we have compared the measurements and the burnup calculations using Serpent- 2 and TRIGLAV codes on 46 different core configurations. An average and the median for Serpent-2 are similar and close to zero, meaning that no systematic discrepancy can be observed. The agreement is relatively good as $52.2 \%$ of calculated coefficients are within $1 \sigma$ and $86.9 \%$ within $2 \sigma$ of the measurements. For TRIGLAV the agreement is not as good as clear systematic discrepancy is observed, which can be caused by TRIGLAV's burnup methodology or the fuel type $8.5 \%$, where higher discrepancies were observed. This will be investigated in the future. As only statistical uncertainty was taken into account in Monte Carlo simulations, further study on propagation of uncertainty in cross section data and $k_{\text {eff }}$ biasing will be done in the future.

\section{REFERENCES}

[1] A. Pungerčič, D. Čalič, and L. Snoj. "STRIGA: A Computer Tool for TRIGA Reactor Burnup Calculations.” In Proceedings of M\&C2019, pp. 641-650. Portland, OR (2019).

[2] J. Leppänen, M. Pusa, T. Viitanen, V. Valtavirta, and T. Kaltiaisenaho. "The Serpent Monte Carlo code: Status, development and applications in 2013." Annals of Nuclear Energy, volume 82, pp. 142 - 150 (2015).

[3] A. Peršič, T. Žagar, M. Ravnik, S. Slavič, B. Žefran, D. Čalič, A. Trkov, G. Žerovnik, A. Jazbec, and L. Snoj. "TRIGLAV: A program package for TRIGA reactor calculations." Nuclear Engineering and Design, volume 318, pp. 24 - 34 (2017).

[4] R. Jeraj, B. Glumac, and M. Maučec. "Monte Carlo Simulation of the Triga Mark II Benchmark Experiment." Nuclear Technology, volume 120(3), pp. 179-187 (1997).

[5] V. Merljak, M. Kromar, and A. Trkov. "Rod insertion method analysis - A methodology update and comparison to boron dilution method." Annals of Nuclear Energy, volume 113, pp. $96-104$ (2018).

[6] L. Snoj, A. Kavčič, G. Žerovnik, and M. Ravnik. "Calculation of kinetic parameters for mixed TRIGA cores with Monte Carlo." Annals of Nuclear Energy, volume 37(2), pp. 223 229 (2010).

[7] T. Goričanec, G. Žerovnik, A. Jazbec, Ž. Štancar, L. Barbot, D. Fourmentel, and L. Snoj. "Validation of neutron flux redistribution factors in JSI TRIGA reactor due to control rod movements." Applied Radiation and Isotopes, volume 104 (2015).

[8] P. Maria. "Higher-Order Chebyshev Rational Approximation Method and Application to Burnup Equations." Nuclear Science and Engineering, volume 182(3), pp. 297-318 (2016).

[9] D. Čalič, G. Žerovnik, A. Trkov, and L. Snoj. "Validation of the Serpent 2 code on TRIGA Mark II benchmark experiments." Applied Radiation and Isotopes, volume 107, pp. 165-170 (2016).

[10] T. Kulikowska. "WIMSD-5B: a Neutronic Code for Standard Lattice Physics Analysis." Distributed by NEA Data Bank Saclay, France (1996).

[11] R. Jeraj, T. Žagar, and M. Ravnik. "Monte Carlo Simulation of the TRIGA Mark II Benchmark Experiment with Burned Fuel." Nuclear Technology, volume 137(3), pp. 169-180 (2002). 